\title{
Conversões da dívida entre os Yawanawá Um modelo de análise dos fundamentos culturais, sociais e políticos da troca'
}

André Vereta-Nahoum

Os Yawanawá, população nativa do sudoeste amazônico, mantêm trocas entre si e com os brancos que envolvem serviços e objetos produzidos internamente, assim como bens industrializados e dinheiro adquiridos por meio de atividades mercantis e transferências estatais. A circulação desses objetos anima e é animada por relações entre si que não subvertem a ordem da comunidade Yawanawá; ao contrário, muitas dessas transações que envolvem dinheiro e mercadorias alimentam vínculos políticos e familiares e motivam a vivência ritualística dessa sociedade.

O propósito deste texto é demonstrar não só o caráter produtivo dessas transações, mas também o trabalho ideológico de subordinação da troca e do consumo a objetivos de reprodução social e cultural. Argumenta-se, portanto, que as transações econômicas estão enredadas em relações sociais e políticas e implicadas em normas culturais, nas quais residem seu sentido último para além de uma satisfação utilitária. Essas relações envolvem afetos, direitos e obrigações, gerando um fluxo de serviços, bens e dinheiro como formas apropriadas de prestação. Por fim, a análise discute tensões resultantes de expectativas diversas envolvendo essas transações.

Em vez de enquadrar as transações em categorias genéricas, como regimes de troca, analisam-se dois pares de conversão da dívida, tendo em mente a perspectiva analítica inspirada na obra de Thomas (1991). Conversão da dívida significa a sequência de

1. A produção deste artigo contou com o apoio da Fapesp, por meio de bolsa pós-doutoral (processo 2014/13285-6). O material utilizado foi coletado com o apoio do Instituto Max Planck para o Estudo das Sociedades. 
prestações que procuram reciprocar os valores recebidos em diferentes registros e esferas sociais, unindo mercado, comunidade, autoridade política, família e ritual. Nessas operações, para compensar uma dívida, o valor recebido é transformado em outro de natureza diversa, circulando em diferentes regimes de troca - por exemplo, bens são frequentemente doados entre parentes para recompensar tarefas de cuidado e criação. Por conversão, entende-se uma transformação que não extingue a dívida, mas dá continuidade à relação e ao fluxo de transações; por dívida, entende-se uma obrigação moral com extensão e forma de cumprimento específicas, ainda que não se estabeleça uma equivalência necessariamente quantitativa entre prestação e contraprestação.

Com base em trabalho de campo, complementado por contatos com alguns indígenas em São Paulo ou por via eletrônica, este texto pretende analisar como, entre os Yawanawá, prestações cingidas por lealdade política, pelas obrigações de criação e cuidado das relações de parentesco, assim como por serviços de proteção e cura, geram dívidas recompensadas com dinheiro, bens ou benefícios e, em contrapartida, a maneira pela qual prestações em bens materiais produzem dívidas convertidas em lealdade política e relações de parentesco, além de cultivar a vida ritual. Essas transações têm lugar em meio a três pares que operam a conversão da dívida.

Embora apoiado em material etnográfico, este texto é uma abstração analítica - e, nesse caso, não há espaço para dar voz aos atores - com o intuito de descrever fragmentos de um sistema de troca, sua lógica de transformações das obrigações e o sentido conferido às transações, aos objetos e ao dinheiro. A primeira sessão discute as vantagens da perspectiva analítica das conversões da dívida e seus contornos. Em seguida, são examinados dois pares de conversão, em que dinheiro e mercadoria complementam outros meios de cumprir as obrigaçóes, o que mostra o quanto as trocas estão subordinadas a visões e relações específicas a cada sociedade. Ao final, são retomados os principais achados que dão suporte ao emprego da perspectiva analítica aqui proposta para outros contextos e circuitos de troca, revelando o enraizamento das transações econômicas em redes de obrigações e afetos familiares, comunitários, políticos e complexos simbólicos.

Conversões da dívida: qual a vantagem?

Para além da análise da lógica cultural local, que orienta os usos e as representações de objetos incorporados por sociedades à medida que integram os fluxos mercantis globais, a proposta aqui é observar como a circulação é engendrada por um complexo de relações políticas, obrigações familiares e comunitárias, preocupações estéticas e complexos simbólicos, alimentando, portanto, essas relações. Dinheiro 
e bens ganham valor no interior dessas relações, como prestações a suas obrigações. Assim, desloca-se a análise dos regimes de trocas e esferas de valor para uma análise das conexões entre elas e as relações que as operam. Como na proposta original de Sahlins, de uma sociologia da troca, transações são tomadas como "um episódio momentâneo em uma relação social contínua” em uma conexão recíproca entre transações e relações sociais, em que estas "podem orientar um dado movimento de bens, mas uma transação específica [...] sugere uma relação social particular” (Sahlins, 1972, pp. 185-186).

Faltam, porém, bons instrumentos analíticos para observar o enredamento das transações econômicas em obrigações, preocupações e afetos que derivam da manutenção de relações interpessoais, políticas e até espirituais.

Há muito percebeu-se que os sistemas de troca que atam pessoas e bens nessas transações são muito mais que comerciais ou econômicos (Frazer, 1922, p. viii), mas essa constatação era oriunda de pesquisas sobre trocas realizadas por sociedades distantes dos centros de produção acadêmica. Ademais, ela serviu para demarcar uma oposição estilizada entre o regime sistêmico que caracteriza as transações ocidentais - a troca mercantil movida pelo interesse utilitário - e seu antídoto, a dádiva - o regime sistêmico de troca dessas sociedades distantes -, associada ao altruísmo dos sujeitos e à inalienabilidade dos objetos, fundando uma dicotomia, ainda que as áreas onde os estudos foram realizados já participassem dos fluxos mercantis globais (Gregory, 1982; Godelier, 1986).

Ainda que fosse ideal-típica (Carrier, 1995), essa dicotomia teve duas consequências analíticas: reservar esses enredamentos entre obrigações rituais, sociais e políticas e transações econômicas nas sociedades ditas arcaicas, além de julgar que a entrada de princípios da troca mercantil e do dinheiro nessas sociedades teria o poder de transformar relações sociais com o mesmo efeito despersonalizador e desagregador que se verificava com a generalização do dinheiro de curso legal como meio de troca nas sociedades capitalistas. $\mathrm{O}$ dinheiro reduziria as esferas de troca e seus critérios qualitativos de valoração, impondo uma equivalência quantitativa (Bohannan, 1959).

Esse consenso persistiu até a década de 1980, quando nova evidência etnográfica foi mobilizada para questionar essa dicotomia. Associações de sociedades com sistemas únicos de troca foram questionadas por análises que revelaram a frequente circulação de objetos em diferentes regimes de troca (Appadurai, 1986; Thomas, 1991) e que todas as sociedades têm transações orientadas para uma esfera de consumo individual de curto prazo e para uma esfera de reprodução social e cósmica de longo prazo (Parry e Bloch, 1989). A abordagem processual de Appadurai (1986) sobre a mercantilização dos objetos permitiu reconstruir os esforços políticos que subjazem à circulação, mas trouxe ganhos limitados para analisar a própria circula- 
ção e as relações que a alimentam. Ademais, as histórias do desentrelaçamento do cálculo econômico mercantil de relações não mercantis (Callon, 1998) e do dinheiro despersonalizado e corrosivo persistem como tropos, com especial força para analisar o advento de transações mercantis e a penetração do dinheiro de curso legal nas sociedades dos outros (Maurer, 2006).

Com a notável exceção do estudo de Gordon (2006) para os xikrin, falar de dinheiro e objetos industrializados nas sociedades ameríndias é afirmar sua corrosão cultural. Em 1997, Ferreira argumentava que, entre os kayabi, os suya e os juruna do Xingu, o dinheiro havia se tornado uma sorte de denominador comum, "um meio arbitrário de comparar quantitativamente coisas desiguais em uma escala que é supostamente comum a elas todas", introduzindo "padrões de valor" que "conflitam com o valor enraizado em sistemas de dádiva recíproca” (Ferreira, 1997, p. 135).

Como afirma Maurer (2006, p. 18), não houve muitos avanços em relação às propostas dos 1980, e mesmo a proposta de Parry e Bloch (1989) de compreender como sociedades representam o dinheiro de diferentes formas não foi completamente adotada. A literatura permanece centrada no estudo das esferas de valor que separam transações e objetos ou em sua corrosão, e, mesmo quando se propõe a investigar a articulação entre laços sociais e transações mercantis, centra sua atenção nas fronteiras fixadas entre relações interpessoais e suas demandas, meios e transferências próprias ou nos esforços para separar o que pode circular e quais os meios adequados de troca a cada relação, como na ideia de "trabalho relacional" de Zelizer (2005).

A chave preponderante para o reconhecimento desses enredamentos tem sido a mobilização do conceito de economia moral, que na sua concepção original, de Thompson (1971) e Scott (1976), se referia a complexos de obrigações e concepções em torno da produção antagônicas e substituídas pela economia de mercado ${ }^{2}$. $\mathrm{O}$ potencial de aplicação é, portanto, reduzido, conquanto recoloca uma adjetivação que restringe esses enredamentos - generalizados, presentes em diversas sociedades como elementos centrais à circulação também mercantil - às economias dos outros ou distingue o complexo de transações analisadas daquelas que ocorreriam nos mercados ${ }^{3}$. O intuito aqui é encontrar formas analíticas de lidar com enredamentos

2. Para uma reflexão sobre os sentidos originais do termo "economia moral" no trabalho de Thompson, ver Götz (2015).

3. L'Estoile (2014) critica uma série de adjetivações semelhantes aplicadas a trocas econômicas de modo a reforçar sua diferença, porém estende essa crítica à pertinência da noção mesma de economia para esses arranjos em que transações se inserem em estratégias distintas de vida. Não apenas o caráter econômico - material - dessas transações é reconhecido, colocando-as em uma esfera de vida própria, como desfazer-se da noção de economia na análise de transações que ocorrem fora dos centros capitalistas equivale a recolocar a dicotomia e pressupor um isolamento de transações que são cortes em fluxos globais de bens (e relações). 
das transações que promovem a circulação material em todas as sociedades, em uma visão da economia no interior de relações que não a adjetiva.

Os conceitos que mais se assemelham à proposta aqui delineada são o de "circuitos de comércio", também desenvolvido por Zelizer (2004), e o de "conversões de valor", inspirado em Bohannan (1959) e discutido por Guyer (2004). A primeira noção refere-se a feixes de laços que compartilham "entendimentos diferentes, práticas, informação, obrigações, direitos, símbolos e meios de troca" (Zelizer, 2004, p. 124). Zelizer não oferece, porém, uma perspectiva analítica clara para explorar esses circuitos e as imbricações entre relações familiares, sociais mais amplas e políticas por eles gerados. A segunda é um conceito que procura acompanhar a criação de valor com base na conversão assimétrica de diferentes bens e serviços que são, paradoxalmente, quantificáveis e medidos a partir de uma escala monetária. Para Guyer, os focos estão na criação de valor em meio a essas conversões e no paradoxo entre a quantificação desses meios de troca - até mesmo com a mediação do dinheiro - e a assimetria das trocas promovidas. As relações alimentadas por essas conversões ficam, porém, em segundo plano.

A vantagem da noção de conversão da dívida reside em seu potencial analítico de representar os fluxos de transações em diferentes regimes de troca e a partir das relações que lhe dão origem. A conversão da dívida corresponde a uma sequência de operações de substituição de objetos e serviços por outros objetos e serviços, às vezes de natureza distinta, promovendo transformações nas relações (Thomas, 1991, p. 49). A noção de conversão da dívida ressalta a multiplicidade das prestações que geram dívida e, assim, alimenta a reciprocidade. Além de atos (serviços e dádivas), há dívidas que decorrem de posições diante de relações, como as de liderança e parentesco.

Também indica, no termo "conversão", o seu caráter de socialidade. Na sequência de transações, dívidas são substituídas por outras. Não há quitação da dívida, mas prestação a uma obrigação decorrente de um ato ou relação, mantendo, tal qual a dádiva maussiana, o vínculo entre partes, mas aqui em diferentes regimes de valor. Tampouco é um pagamento no sentido de ter um valor quantitativamente equivalente à obrigação. Ainda assim, o termo "dívida”, como na conceituação de Graeber (2011), aplica-se aqui porque se trata de uma obrigação moral em aberto que exige uma prestação de forma (serviços, bens, reconhecimento de uma relação) e extensão apropriadas. O hábito informa os participantes a respeito do que e quanto se tem de oferecer para reduzir a dívida, reciprocar a prestação que lhe deu origem e, assim, manter a relação.

Conversões obedecem a uma razão prática, a escalas culturais e sociais de valores e a códigos vinculados a deveres de parentesco, de criação, mágico-religiosos, de 
lealdade comunitária e política. Ainda que possam envolver trocas mercantis, bens com valor pecuniário e o próprio dinheiro em suas cadeias, não há a introdução de um princípio de equivalência quantitativa entre prestações e contraprestação nas conversões nem a substituição de sistemas de classificação de objetos em relação às obrigações pelo seu valor pecuniário. Algumas das prestações, como o afeto ou a lealdade política, sequer são representadas em valores quantitativos. Nas relações que ensejam essas transações, o interesse material é secundário em relação ao que se afirma estar em jogo: a manutenção de boas relações, o respeito às forças que garantem a subsistência e a saúde, o reconhecimento da honra e o senso de comunidade. Logo, não é adequado cobrar um valor material ou uma equivalência quantitativa. Os procedimentos possíveis para recordar que há uma dívida aberta são circunlóquios, sugestões sutis que jamais fazem referências a valores ou objetos, mas apelam a emoções, a vínculos e à intimidade entre as partes envolvidas. Essas cobranças apelam para os deveres impostos pelo código moral das relações, os afetos e as lealdades. A utilidade do conceito ganha maior concretude na análise de algumas conversões operadas pelos Yawanawá.

As conversões da dívida: alguns cortes no fluxo

Em qualquer sistema social de troca - e com mais razão em um sistema global de circulação - há uma miríade de prestações e contraprestações que fazem pessoas e bens circularem, em cumprimento a obrigações de diferentes naturezas e em múltiplos regimes de troca. Há, por assim dizer, fluxos contínuos de conversões das dívidas à medida que bens, riquezas, serviços e ritos circulam em relações em todas as direções (prestações e contraprestações, dos deveres de criação e cuidado ao mercado e do mercado aos deveres de criação e cuidado). Ainda que sejam relações, e as obrigações a elas ligadas, que dão ensejo às prestações, gerando dívidas reciprocadas com outras prestações, não há um ponto de origem único para esses fluxos de conversões. Como salientado por Thomas (1991, p. 37), diferentemente dos sistemas de troca polinésios descritos por Malinowski (1922) e Mauss (2003), não há um gerador único - e primeiro - da dívida, mas um conjunto de múltiplas prestações - referentes a relações - que produzem dívidas. Logo, qualquer análise das conversões da dívida é um corte que tem por ponto de partida arbitrário algumas relações específicas selecionadas, porque vinculam uma população ou fazem circular um bem ou serviço de interesse do analista. Trata-se de um fragmento formado por um conjunto discreto de conversões do fluxo contínuo que, entretanto, permite verificar os enredamentos das transações econômicas - e não apenas das dádivas - com relações sociais e políticas, obrigações religiosas e preocupações estéticas. 
Aqui são escolhidos dois pares de conversões no interior do sistema de trocas estabelecidos entre os Yawanawá e desses com populações externas. A escolha é justificada pela centralidade que essas operações possuem para sua reprodução sociocultural e também para os movimentos de objetos e serviços produzidos pelos Yawanawá, aqueles adquiridos nos mercados e o dinheiro. Cada um desses pares congrega duas conversões que têm lugar nas mesmas relações e correspondem aos dois vetores das transações - a prestação e a contraprestação, ou a transação e os serviços ligados a uma relação específica, como mostra Sahlins (1972) - que essas relações encetam (Quadro 1). O primeiro par corresponde à conversão da dívida de lealdade política em dívida material e da conversão inversa, em que bens e dinheiro são colocados a serviço da produção de liderança política. $\mathrm{O}$ segundo par corresponde à conversão da dívida gerada pelo compartilhamento de conhecimento espiritual e de tratamento (serviços de cura e realização de rituais), dádivas de mercadorias e dinheiro e observância de interditos alimentares e sexuais, bem como a conversão dessas em cura, conhecimento, rituais e êxito na caça e na pesca.

QUADRO 1

Conversões da divida Yawanawá

\begin{tabular}{llcl}
\hline & RELAÇÃo PESSOAL E SERVIÇOS & CONVERSÃo & OBJETO \\
\hline 1 & Liderança política & $\leftrightarrow$ & Mercadorias, dinheiro e empregos \\
2 & Conhecimento, cura e rituais & $\leftrightarrow$ & $\begin{array}{l}\text { Parentesco, mercadorias, dinheiro, } \\
\text { interditos alimentares e sexuais }\end{array}$ \\
\hline
\end{tabular}

Um terceiro par não será aqui analisado por se tratar de uma conversão muito explorada na literatura: a transformação da dívida gerada por relações de parentesco que envolvem cuidado, criação e afeto - em contrapartidas na forma de mercadorias, alimentos e dinheiro. Diferentes pesquisas, como a de Zelizer (2005), Weber (2013) e Guimarães (2016), revelam que a coabitação e as relações de parentesco produzem um emaranhado de prestações materiais e afetivas de cuidado, assim como a formação de um fundo mútuo. Evidentemente, há especificidades sobre a maneira pela qual valores são marcados como preferenciais para produzir e reproduzir laços de parentesco, mas não há espaço para aqui explorá-los.

Esses são vetores de circulação de objetos, serviços e pessoas em diferentes regimes de valor que permitem verificar a domesticação de processos produtivos, dos objetos dos brancos e do dinheiro para produzir ordem e poder político, laços de parentesco e de comunidade, a cura e o ritual. Antes, porém, algumas palavras a respeito dos Yawanawá são necessárias. Trata-se de uma população pertencente 
ao grupo linguístico pano, habitantes das margens do alto rio Gregório, na porção oriental da bacia do rio Juruá, região central do Acre, pelo menos desde o final do século XIX. A partir de 1984, eles passaram a compartilhar com um pequeno grupo de katukina uma terra indígena demarcada (Terra Indígena do Rio Gregório). Sua localização e composição atual, incorporando outros nativos da região e colonos, são o resultado de movimentos de dispersão, reunião e fusão, por meio de alianças, predação e estratégias de sobrevivência das correrias na transição entre os séculos XIX e XX, incursões violentas de forasteiros para controlar as terras e seu recurso mais valioso naquele momento: a borracha, extraída da hévea nativa (Erikson, 1993; Naveira, 1999). Desde então, os Yawanawá se engajaram no comércio de produtos florestais com forasteiros, quase sempre em troca de objetos industrializados, e com a intermediação de seus líderes, que reuniam a produção, adquiriam bens e distribuíam para a comunidade.

A população de aproximadamente setecentas pessoas (em 2013) divide-se em sete vilas ao longo do alto rio Gregório, desde suas nascentes até o limite norte do território demarcado, exigindo horas de viagem com barcos motorizados até a principal estrada do estado, distante da cidade mais próxima, Tarauacá. As duas últimas aldeias, Mutum e Nova Esperança, concentram a maior parte da população e a infraestrutura disponível (escolas, açudes de peixes, acesso à internet por satélite e geradores elétricos). Ali recebem visitas e realizam festividades anuais que reúnem centenas de visitantes. Encontram-se também as sedes locais de duas organizações que representam os Yawanawá nas instituições estatais, cada qual associada a um chefe, em uma dinâmica que alterna cooperação e competição por oportunidades no mercado e benefícios governamentais. A população divide sua lealdade entre esses dois líderes, mas essa dupla representação não acarreta divisões sociais internas, já que laços familiares e comunitários se estendem a pessoas ligadas a essas organizações e a todas as aldeias.

A relação dos Yawanawá com os objetos dos brancos e o dinheiro é marcada pela distância de mercados, que faz com que o dinheiro seja escasso e menos valorizado do que os bens, sobretudo aqueles que lhes permitem vencer distâncias e são instrumentos para obter recursos florestais pela caça, pesca e extração. Essa relação é também produto de sua experiência histórica de trocas de produtos florestais. Ainda que possam extrair da floresta e de seus roçados o necessário para sua sobrevivência, a troca de algum produto ou serviço com forasteiros é considerada um meio para se obter aquilo que a floresta não oferece. No geral, esses bens não enfrentam reservas morais, desde que considerados condizentes com o bem-estar coletivo e a manutenção da estrutura política, normas sociais e culturais. Como no caso fijiano descrito por Parry e Bloch (1989, p. 28), o consumo (e o dinheiro) é justificado quando dirigido 
à reprodução social, mas se torna objeto de censura quando promove negligência do parentesco e da liderança política ${ }^{4}$. Assim, dinheiro e bens têm sido utilizados não apenas para a reprodução do parentesco, mas também para a produção de conhecimento e rituais, como será analisado a seguir.

Conversão 1: entre dívida política e dívida material - os bens para produzir o poder político

A liderança Yawanawá parece repousar, entre outros elementos, na capacidade de administrar de maneira eficaz as trocas e produzir um fluxo contínuo de benefício para a comunidade. A relação entre o chefe e a comunidade, por meio da qual se transforma a dívida gerada pela distribuição de bens, recursos e benefícios - tarefa realizada pelo líder - em uma dívida de lealdade política - que alicerça seu poder - é central na circulação de produtos dos Yawanawá para mercados externos e vice-versa, de produtos externos, incluindo dinheiro, para a comunidade. Não apenas a dívida material transforma-se em dívida política: a manutenção da posição de liderança da relação que origina a dívida - depende de prestações materiais para compensar a lealdade política.

Para que isso seja possível, o líder precisa ter boas relações com entes de governo ou ser capaz de organizar um excedente a ser intercambiado nos mercados. No primeiro caso, as relações com políticos e burocratas dos três níveis federativos facilitam a implementação de benefícios individuais (como empregos públicos na aldeia ou prestação de serviços de saúde) e coletivos (como escolas, geradores elétricos, pontos de acesso à internet, açudes de criação de peixes e um posto de saúde). Já a produção de excedentes exige a organização dos esforços da comunidade para o trabalho e, por isso, este par de conversão integra uma sequência mais ampla de transformações com origem na relação entre o líder e a comunidade: a produção de excedente pela população gera um crédito perante o líder; esse excedente é trocado nos mercados por bens e dinheiro, então distribuídos no interior da comunidade, honrando a dívida com os produtores e, ao mesmo tempo, produzindo uma dívida de lealdade política em favor do chefe (Quadro 2, item 1).

Como essas operações são simultâneas, as partes envolvidas tendem a compreender as prestações com base em uma dessas conversões, um fragmento na sequência ampla, o que gera muita controvérsia. Líderes e parte da comunidade envolvida nas atividades produtivas revelam visões distintas sobre a natureza da dívida, da prestação (pagamento ou dádiva) e da forma de mensurá-la. Chefes e um círculo restrito de

4. Os dilemas e discussões em torno da circulação do dinheiro e, sobretudo, de diferentes objetos industrializados no interior das comunidades Yawanawá é discutido em profundidade em Vereta-Nahoum (2016). 
colaboradores entendem a circulação como uma conversão característica do clientelismo, e a distribuição de bens e dinheiro como dádiva política, em que a generosidade revela a proeza nas trocas e produz uma dívida de lealdade (Quadro 2, item 2). Para eles, a distribuição de bens obtidos com a troca é uma dádiva que precisa guardar apenas uma vaga equivalência com o grau de empenho e, sobretudo, a densidade dos laços estabelecidos com o líder. Outros membros produtivos da comunidade colocam-se, porém, na condição de trabalhadores, compreendendo a relação como característica do trabalho remunerado. Os bens e o dinheiro distribuídos são, portanto, interpretados como uma compensação pelo esforço passado ou futuro, devendo guardar equivalência mais ou menos exata com este. Ademais, a lealdade aos chefes é considerada um sinal de reconhecimento à sua capacidade de criar oportunidades de renda para a população (Quadro 2, item 3).

QUADRO 2

Sequência de transformações e variações da conversão entre dívida material e política

\begin{tabular}{l}
$\begin{array}{l}\text { 1. Trabalho } \begin{array}{l}\text { (organizado pelo líder) } \\
\text { 2. Mercadoria, dinheiros } \\
\text { e empregos }\end{array} \\
\begin{array}{l}\text { 3. Trabalho } \\
\text { (trocado pelo líder) }\end{array}\end{array} \quad \begin{array}{l}\text { Lealdade política } \\
\text { (distribuídos pelo líder) }\end{array} \rightarrow$ Lealdade política \\
\hline
\end{tabular}

Não se pode estabelecer se as características da liderança são um aspecto arraigado do sistema político Yawanawá ou fruto de relações com os colonizadores. De toda sorte, o arranjo estabelecido por iniciativa de líderes Yawanawá do passado com seringalistas da região e seus próprios homens consolidou o padrão de conversão da dívida material em obrigação de lealdade política e as duas visões mencionadas das sequências de transações. Os Yawanawá passaram a esperar bens por seu trabalho produtivo para o mercado e a oferecer trabalho enquanto houver um fluxo de bens para a comunidade. O líder consolidou-se como intermediário desse sistema de troca, e essa posição garante proeminência que obriga à lealdade e à obediência 5 .

Existem informações sobre quatro líderes e um pretendente a líder que fracassou ${ }^{6}$. Todos mantiveram relações com não nativos, e a principal diferença entre os quatro

5. A natureza específica do vínculo entre chefia e comunidade é um tema clássico da etnologia amazônica, com ampla produção (ver, entre outros, Lévi-Strauss, 1955; Clastres, 1974; Granero 1993; Sztutman, 2012). Mais pertinente que discutir a aderência a esses modelos é analisar a evidência de que o poder repousa em uma dívida material, e, assim, liderança política e êxito mercantil estão imbricados, revelando a conversão aí contida.

6. Os dados históricos disponíveis advêm tanto de relatos verbais e de documentos como de um livro publicado pelos Yawanawá (Vinnya et al., 2006) e do laudo antropológico de revisão dos limites da Terra Indígena do Rio Gregório (Fundação Nacional do Índio, 2006). Esses achados são, ademais, corroborados pela etnografia junto aos Yawanawá produzida por Naveira (1999). 
que obtiveram respeito e autoridade e aquele que não se sagrou líder foi a proeza na administração de sistemas de troca de modo a distribuir bens à comunidade. Em meio a disputas pelo poder, os atributos que fazem um homem se destacar e que definem um líder também são discutidos, e outros elementos, como a descendência agnática, o domínio do sistema médico e espiritual e a destreza na caça e pesca, que revela um conhecimento do território, são invocados. Quatro dos homens aqui mencionados pertencem à mesma linhagem, mas um deles foi preterido pelo próprio pai em benefício de um dos atuais líderes. Todos os outros, por sua vez, revelaram que a capacidade de gerar um crédito perante a sociedade, sob a forma de cura, alimentos ou bens, é fundamental para produzir uma liderança. Logo, antes de relativizar, confirmam a importância de variações da dívida para produzir lealdade política.

O primeiro deles é Antônio Luiz, lembrado como o Yawanawá que estabilizou as relações com o "patrão" seringalista após conflitos entre posseiros na região. Os Yawanawá tinham interesse nos objetos de que dispunham os brancos; o "patrão", em evitar conflitos com os nativos. Antônio Luiz foi, portanto, criador de um novo circuito de trocas, estabelecendo-se como intermediário dos Yawanawá e outros grupos nativos na região perante o "patrão". Capaz de manter uma excelente relação com o "patrão" e os seringueiros não nativos, o que incluía vínculos morais não limitados à troca material, foi batizado e pôde, em temporadas de boa produção de borracha, viajar ao grande mercado amazônico da época, Belém, a fim de adquirir produtos para sua comunidade. Apesar das dívidas com o seringalista, esses vínculos garantiam-lhe o direito de obter objetos indispensáveis no barracão e de pedir ajuda em caso de necessidade.

Esses são lembrados como tempos de introdução de novos objetos e de generosas festas onde se reuniam nativos e não nativos. Com essas festas e casamentos com mulheres de grupos vizinhos, Antônio Luiz procurou estabelecer alianças e ampliar trocas. Ele é lembrado, também, como um poderoso curandeiro, capaz não só de curar mas também de causar danos a inimigos, revelando a imbricação entre poder político e de cura. Quer por sua generosidade na distribuição de bens trocados pela borracha, quer por sua capacidade de cura, ele foi eficiente em produzir dívida e gerar lealdade.

Seu filho, Raimundo Luís, tornou-se líder em tempos mais difíceis. A região foi alvo, nos anos de 1970, de programas de regularização fundiária e incentivo fiscal. Um novo proprietário do sul do país estabeleceu restrições de acesso aos recursos florestais na área e estabeleceu controle mais rígido sobre os bens adquiridos no barracão. Com maior dificuldade para distribuir bens, Raimundo perdeu o monopólio da troca da borracha e teve sua autoridade questionada pelos irmãos. Ocupando colocações próprias, passaram a negociar diretamente no barracão e mudaram-se com suas 
famílias alargadas para novos aldeamentos. Ele nunca terminou a formação para se tornar curandeiro, e sua conversão ao cristianismo afastou-o das práticas espirituais. Assim, Raimundo não conseguiu, como o pai, produzir continuamente uma dívida na forma de bens ou de cura. Apesar disso, ele é lembrado como um líder generoso, sempre compartilhando a produção de seus roçados e os instrumentos de trabalho. Ao falar sobre isso, seu filho, Raimundo Sales, sintetiza a fórmula do prestígio que, por meio da dívida, produz lealdade: “[ele] não tinha prazer em ter. Só em dar. Ele dava muitas roupas, terçados. [...] Ele não sabia comer sozinho, sempre compartilhou a comida. [...] Quando alguém aparecia com necessidade, ele não conseguia fechar os olhos. A gente estava sempre na casa de papai pedindo ajuda”.

Raimundo Luís procurou, também, intermediar as relações da comunidade com novos atores e instituições presentes na região. Aceitou, por exemplo, o estabelecimento da missão protestante Nova Tribos do Brasil, organização cuja atividade na região é lembrada com ambivalência, pois ao mesmo tempo que prestavam serviços médicos relevantes, reprimiam práticas de cura e jogos tradicionais. Foi também ele que, a partir dos primeiros contatos com a Fundação Nacional do Índio (Funai), decidiu reivindicar a demarcação de sua terra, o que aconteceu em 1984.

Com a ampliação do reconhecimento dos direitos indígenas na década de 1980, instituições estatais tornaram-se mais relevantes para negociar benefícios. Era necessário saber navegar pelas instituições dos brancos para obter direitos e benefícios, o que levou Raimundo a enviar dois membros de sua comunidade para Rio Branco, imbuídos da missão de aprender a reivindicar direitos e negociar melhores condições com os "patrões”. Um deles era seu filho Sales que, apesar da pretensão, não conseguiu substituir o pai na liderança. Sales participou do movimento indígena do Acre, incorporando-se depois ao escritório regional da Funai, mas nenhuma dessas posições lhe permitiram amealhar recursos materiais para a comunidade. Depois da expulsão dos posseiros da terra em meio à sua demarcação, Sales tornou-se um dos intermediários responsáveis pela comercialização direta da borracha e outros produtos florestais, além de propor uma série de projetos para obtenção de renda na comunidade. Porém, o descontrole na administração dos recursos obtidos e acusações de consumo excessivo de álcool nas cidades deram-lhe uma má reputação na comunidade. Sales não só falhava em distribuir bens, mas também subvertia o princípio que subsume os empreendimentos comerciais dos Yawanawá, assim como o consumo de bens ao atendimento de necessidades e a reprodução de vínculos familiares e comunitários. Cristão como o pai, Sales jamais se interessou pelo conhecimento espiritual e, portanto, também não foi capaz de gerar uma dívida por esse meio.

O outro jovem Yawanawá enviado à cidade, Biraci, foi mais bem-sucedido. Integrando-se à constelação de movimentos sociais de luta por reconhecimento 
e acesso aos recursos florestais contra iniciativas de desenvolvimento na região, ele se mostrou um hábil articulador, dominando tanto a linguagem dos direitos e benefícios, como a dos negócios. Representou o movimento indígena em diversas reuniões nacionais e internacionais, incluindo eventos paralelos à Conferência das Nações Unidas sobre o Meio Ambiente e Desenvolvimento, no Rio de Janeiro em 1992. Foi lá que conheceu o fundador de uma empresa estadunidense de produtos de beleza, interessado à época em pigmentos naturais para substituir os compostos derivados de petróleo utilizados em tinturas capilares e produtos de maquiagem.

Como seu intrépido avô Antônio Luiz, Biraci propôs uma parceria comercial para produzir urucum, utilizado nas pinturas corporais Yawanawá como forma de proteção espiritual. O fim de subsídios federais havia levado ao abandono da produção de borracha e, em busca de renda para suprir as necessidades, os Yawanawá viviam dispersos. Os benefícios oferecidos pela empresa - como placas solares, máquinas e uma clínica, além da receita que seria convertida em bens disponíveis em um armazém - atraíram os membros da comunidade a reunirem-se em torno da produção de urucum, resultando no encontro da maior parte deles em uma única aldeia. Assim Biraci foi consagrado líder, reconhecido pelo próprio Raimundo Luís em substituição ao filho. Para selar sua posição, ele promoveu ainda uma aliança matrimonial com Raimundo Luis, casando-se com uma de suas filhas. Como genro, Biraci devia prestações na forma de alimentos e bens e estava ligado ao fundo familiar do antecessor.

Biraci administrou o sistema de trocas em seu favor, animando a comunidade em torno de um esforço produtivo e distribuindo bens; como retorno, ganhava lealdade. Além da comercialização de urucum, ele era profícuo na promoção de alianças, que promoviam a circulação de objetos e a conversão de bens e serviços internos em ganhos materiais e simbólicos para a comunidade. Mercado e Estado são instrumentais e complementares para gerar recursos a serem distribuídos. Consciente do valor de suas práticas espirituais - ele próprio era iniciado -, Biraci fez acordos com representantes do Santo Daime e centros esotéricos urbanos que compartilham o uso da ayahuasca, bebida alucinógena usada pelos nativos amazônicos para se comunicar com espíritos e curar doentes. Promovendo apresentações de rituais Yawanawá em seu próprio território ou alhures, Biraci continua a forjar novos aliados e atrair recursos. Apoiado em boas relações políticas estaduais, ele também deseja não só atrair benefícios comunitários na forma de obras, como geradores elétricos e açudes para criação de peixes, mas também benefícios a serem distribuídos a leais seguidores, como cargos de professor, agente florestal e de saúde.

Atualmente, Biraci divide a liderança com Joaquim, que também exerce funções de representação e intermediação, gozando de autoridade e revelando a lógica competitiva e a natureza frágil do poder. Filho mais jovem de Raimundo Luis, ele 
foi educado em meio urbano e passou uma temporada nos Estados Unidos para aprender inglês, já que era preciso um intermediário que que dominasse a língua para melhorar o contato com a nova empresa pareceira. À medida que conflitos entre a empresa e os envolvidos na produção do urucum enfraqueceram o controle de Biraci sobre o projeto, Joaquim assumiu a posição, reorganizando a produção em outras aldeias. Enquanto Biraci promovia apresentações culturais e negociava com o governo estadual, Joaquim se consolidou como o segundo líder com a promessa de distribuir os recursos materiais advindos da produção de urucum. Como Biraci, Joaquim também consolidou sua posição buscando no mercado e com órgãos estatais oportunidades de renda e benefícios para a comunidade. Ele é, quiçá, quem melhor revela a importância, para a liderança, de se produzir uma dívida material, já que, longe das práticas espirituais e vivendo nas cidades, Joaquim não dispõe de outros meios para sustentar seu poder político.

A trajetória desses líderes revela a imbricação dos projetos de formação de liderança política com esforços para promover circuitos de troca. Para destacar-se dos demais, garantir respeito e encorajar os esforços produtivos da comunidade, o líder precisa ser generoso na distribuição de recursos. Para tornar-se grande, não basta obter os recursos, é necessário doá-los. O padrão de consumo estabelecido nas aldeias está ligado a esse fato, e mesmo o líder não deve mostrar muitos bens a menos que pretenda doá-los. Nesse sentido, a casa de Biraci tem uma área aberta aos visitantes, onde se expõem bens que serão distribuídos, além de receber diariamente, em sua cozinha, os homens mais leais e as mulheres que pedem alimento.

Assim, valores obtidos por meio de agências estatais, dádiva e trocas mercantis são convertidos em lealdade política. A tensão que se coloca, entretanto, é a respeito da natureza da transação que forma a dívida entre os líderes e os membros da comunidade. Os primeiros consideram-na um dom e, como tal, é capaz de gerar o sentimento de solidariedade e, como ressalta Godelier (1996), de superioridade. Os segundos interpretam-na como uma compensação por trabalho. O êxito com que um líder consegue sustentar a primeira hipótese é elemento auxiliar da manutenção de seu poder.

A transformação aqui analisada estabelece um princípio de reciprocidade generalizada, nos termos de Sahlins (1972, pp. 193-194): as prestações são consideradas altruísticas, as dívidas não podem ser direta e abertamente cobradas e a contraprestação não é determinada em termos de qualidade, quantidade ou prazo. Por um lado, líderes esperam lealdade, sobretudo quando são bem-sucedidos em obter e distribuir recursos. Por outro, os Yawanawá esperam receber uma compensação pelo seu esforço produtivo. Outra consequência dessa imbricação é a existência de um princípio de distribuição de recursos que se assemelha ao clientelismo, 
pois acaba favorecendo os membros mais próximos e leais. Entretanto, a adesão e o compromisso com as atividades produtivas coletivas fortalecem o vínculo, ampliando o acesso a recursos.

Como em outros casos, a cobrança de dívidas só pode ser feita de forma indireta ou por meio de certos rituais. Aos trabalhadores restam sugestões, a troca de lealdade e a interrupção do trabalho. Líderes possuem mais recursos, pois podem suspender a partilha de bens e benefícios ou recordar aos Yawanawá a importância de sua intermediação em prol da comunidade, ou seja, sugerir a existência de dívidas abertas. Biraci frequentemente busca reafirmar sua liderança e incentivar demonstrações de lealdade, o que acontece durante refeições em sua casa ou em espaços abertos onde recebe muitos convidados - a comensalidade já é um sinal de fidelidade. Essas ocasiões são propícias para discursos solenes, quando Biraci enumera as vantagens de suas ações para a comunidade. Ele lembra a todos não só sua lisura nas negociações com o governo estadual acerca de obras para as aldeias e da criação de cargos públicos, mas também a generosidade com que distribui recursos amealhados. Quando anunciou que havia sido convidado para assumir o cargo de assessor estadual de saúde indígena, ele imediatamente sugeriu aos jovens os benefícios de serem leais: "aqueles que nunca estiveram comigo, eu não lembro, eu não penso neles”.

Conversão 2: a conversão de serviços de cura e conhecimento (rituais e práticas) em laços de parentesco, mercadorias, dinheiro, assim como interditos alimentares e sexuais

Outro conjunto de conversões que anima a circulação de bens e dinheiro envolve os Yawanawá, seus aliados, objetos e também os espíritos da floresta em torno de rituais e práticas de cura, além do conhecimento necessário para realizá-las. Assim, a dívida gerada pelo conhecimento compartilhado, por um serviço de cura ou, ainda, pela performance de um ritual pode ser recompensada sob a forma de doação de esposas, bens e dinheiro. A aquisição desse conhecimento ou mesmo a cura exigem, ademais, o respeito a um conjunto de prescrições comportamentais, cujo descumprimento pode desagradar os espíritos e, consequentemente, gerar fraqueza, doença e até mesmo a morte. Há interditos contra uma gama de alimentos ou contra relações sexuais durante o processo de iniciação, visando a fortalecer os corpos para a comunicação com os espíritos e demonstrar respeito.

Os Yawanawá possuem um complexo sistema de cura descrito por Gil (1999), em que espíritos, ou yuxin, de animais e plantas nativas dotadas de personalidade e consciência são ativados para produzir visões e conhecimento. Um curandeiro, ou xinaya, deve ser capaz de compreender e guiar os espíritos. Isso exige um grande fortalecimento corporal. A iniciação é um longo processo que envolve o afasta- 
mento do aprendiz da comunidade, rígidos interditos sexuais e uma dieta restrita, que consiste, fundamentalmente, na ingestão de uni, bebida alucinógena também conhecida por ayahuasca ${ }^{7}$.

A aquisição desse conhecimento depende de renúncias pessoais e da observância de um código comportamental estrito. Esses sacrifícios são oferecidos ao espírito-guia do uni, o muka vãine, que, contido no cipó utilizado para produzir a bebida, orienta os iniciantes e permite que se comuniquem com os demais espíritos da floresta. Essas exigências comportamentais têm um duplo sentido: servem para fortalecer o corpo (Gil, 1999) e são uma retribuição ao conhecimento oferecido pelo muka, como acontece em outros sistemas de culto em que as oferendas procuram retribuir ou solicitar ações de entidades metafísicas. Aqui também não há equivalência quantitativa possível entre prestações e, em uma relação necessariamente desigual, não se cobra nada do espírito ${ }^{8}$, atribuindo-se qualquer falha a alguma ação ou omissão do iniciante. Assim, e ainda que esse tema seja controverso entre os Yawanawá, antigo líder Raimundo Luiz era tido por seus irmãos e outros contemporâneos como um curandeiro sem poder de cura por haver violado sua dieta e não ter ingerido o coração de uma sucuri, parte fundamental da formação, como descrito por Naveira (1999) e confirmado por muitos indígenas. Essa falha teria interrompido o processo de aquisição de conhecimento e é associada a futuros problemas de saúde e à sua morte.

As relações e as conversões da dívida envolvidas na obtenção do conhecimento não se restringem, porém, apenas a iniciantes e espíritos. Durante a iniciação, aprendizes são acompanhados e guiados por xinayas experientes. Apenas dois nonagenários Yawanawá, Tatá e Yawarani, possuem esse título, havendo herdado esse conhecimento de Antônio Luiz. Considerados os únicos xinayas completos, eles detêm o controle sobre o conhecimento da cura, sendo, portanto, indispensáveis aos que decidem empreender a iniciação para se tornar curandeiros. Interessados na formação xamânica precisam persuadir Tatá ou Yawarani a guiá-los no processo. Relações de parentesco e deveres de cuidado são invocados ou assumidos quando se solicita esse tipo de serviço. Alianças matrimoniais com o curandeiro ou sua família eram e continuam a ser celebradas por quem deseja obter tal conhecimento. Um

7. A ayahuasca é uma bebida fermentada composta pela combinação da Banisteriopsis caapi com folhas de diferentes arbustos. No caso dos Yawanawá, são utilizadas folhas de Psychotria viridis, conhecida regionalmente como chacrona.

8. É particularmente evocativo desse fato o episódio de Jó contido nos textos sagrados das três religiões abraâmicas. A alegoria revela que a observância dos mandamentos não gera qualquer pretensão de contraprestação na forma benefícios ou favores da divindade. Ainda que não se afirme que a essência das divindades seja a mesma em todos os sistemas religiosos, o episódio revela que, também para os seguidores dessas religiões, o bom crente é temeroso e oferece resignadamente o que lhe é exigido do Criador, sem exigir nada em troca. 
Yawanawá que pertença ao grupo familiar do xinaya tem a pretensão de solicitar esse conhecimento, assim como serviços de cura, quando necessários. Em alguns casos, uma mulher pode ser oferecida para o xinaya ou sua família. Há, portanto, uma conversão entre dívidas produzidas por alianças matrimoniais e uma prestação sob a forma de conhecimento espiritual.

Dois casos podem esclarecer melhor essas relações. Waxy Yawanawa, que iniciou sua formação e dieta em 2013, orientada por Tatá, contou-me que convencê-lo não havia sido difícil, mesmo sendo a última pessoa a se unir a um grupo de jovens uma verdadeira classe de treinamento - que desejavam adentrar nos ensinamentos do sistema de cura. Uma de suas irmãs é casada com Tatá e, logo, ele aceitou a sua presença. Antes dela, duas outras mulheres haviam estado no samakei, espaço sagrado e recluso de formação. Por outro lado, Augusto Pereira, hoje considerado um conhecedor das plantas medicinais, jamais conseguiu obter essa formação. Ele mudou-se para a comunidade após se casar com uma Yawanawá, e suas relações de parentesco com os curandeiros, primeiro Antonio Luiz, depois Tatá e Yawarani, eram muito fracas. Nenhum deles quis ensiná-lo, razão pela qual se tornou um autodidata, procurando plantas e enfrentando alguns passos do processo iniciático sem ter qualquer orientação (Gil, 1999, p. 30).

A dívida pela aquisição do conhecimento não se esgota, porém, nas prestações sob a forma de afeto e cuidado que caracterizam as relaçóes familiares. Seja pelo conhecimento partilhado, seja pelos serviços de cura, os xinayas são merecedores de cuidados especiais da comunidade. A eles não faltam alimentos, remédios e atenção à saúde. Líderes ocupam-se de seus deslocamentos em caso de doença.

As relações interétnicas e o crescente interesse de grupos urbanos pelas práticas espirituais ameríndias, sobretudo por causa do uso de substâncias alucinógenas, chamadas de plantas de conhecimento e cura, inseriram novos elementos nesse cenário e ampliaram as trocas que subjazem à circulação do conhecimento. Se antigamente o conhecimento era um bem valioso por ser a única forma de cura, hoje seu valor está mais ligado ao potencial de permitir aos iniciados circularem e produzirem novas alianças a fim de garantir ganhos materiais. Tornar-se praticante de rituais é atualmente o mais promissor projeto profissional da comunidade, tanto para conquistar reconhecimento interno como para criar oportunidades de geração de renda.

Além de ampliar o número de Yawanawá que procuram a formação espiritual, os líderes passaram a integrar essas relações, em razão de seu papel como representantes e formadores de alianças com grupos esotéricos. Cada um dos líderes permanece próximo a um dos xinayas, e ambos são consultados sobre a inclusão de novos membros na iniciação ou sobre sua saída da comunidade para performances. Biraci, ele próprio iniciado, tornou-se um agenciador entre curandeiros e aliados no Brasil e no exterior. 
Assim, a circulação do conhecimento e da cura gera também a conversão de uma dívida de conhecimento em uma dívida de lealdade política. Essa conversão é intermediada pelo fluxo de bens e dinheiro proporcionado por serviços de cura e apresentações.

Nos serviços de cura, mais um vez, verificam-se conversões da dívida entre três entes. Espíritos oferecem a visão que permite a cura, mas, para isso, doentes e curandeiros observam os interditos alimentares e sexuais. Os mesmos cuidados são, aliás, oferecidos por caçadores que querem o auxílio desses espíritos na caça, e a cura pode atingir até os maus caçadores, que sofrem com a panema, isto é, resultado de violações às obrigações comportamentais. A energia necessária para a cura exige que o curandeiro se abstenha de relações sexuais e de uma série de alimentos, sobretudo os doces. Por meio de seus atos de fala, durante o ritual, o curandeiro utiliza o yuxin - o espírito do uni - a fim de produzir visões no paciente que, narradas a ele, indicam o diagnóstico. Além de recorrer a esse espírito como meio de comunicação e interferência nos espíritos causadores da doença, o curandeiro realiza uma série de sopros no corpo do doente. Observar tais interditos é fundamental para manter o respeito e os favores dos espíritos; para os caçadores, em particular, isso é imprescindível, já que eles dependem dos espíritos para encontrar a caça.

Entre o curandeiro e o doente há também diferentes transações: a cura pode ser oferecida a alguém do círculo familiar restrito em observância ao dever de cuidado, mas será considerado um serviço para os demais. Em ambos os casos, será recompensado com bens; no segundo, sobretudo dinheiro, muitas vezes imediatamente após o serviço prestado, como ocorre quando se compra uma mercadoria.

A dívida relativa a apresentações de rituais e serviços de cura para não nativos gera principalmente a formação de alianças, as quais resultam em um fluxo de doações materiais e simbólicas. Em alguns casos, requer-se uma contribuição pela participação no ritual, sobretudo quando realizado em centros esotéricos nas cidades, mas não se fala em "preço", pois se trata de uma "contribuição pela experiência”. Entretanto, a dívida gerada por esses serviços é convertida para ampliar a participação dos Yawanawá nesses centros esotéricos, onde as novas alianças são mobilizadas para defender direitos, conceder benefícios à comunidade Yawanawá e ampliar o fluxo de doações materiais, próprio de amizades. Serviços de cura realizados fora da comunidade, desde que fora do círculo familiar, também são considerados "trabalhos" recompensados materialmente. Kuni, Hushahu e Waxy, curandeiros que acompanhei, faziam numerosos serviços dessa natureza em suas viagens por cidades brasileiras. Certa vez, Waxy me disse que estava em São Paulo "para fazer trabalhos, para eu poder ajudar a comunidade e melhorar as condições na aldeia sagrada". Por "ajuda" e "melhoria", ela me explicou mais tarde, que estava se referindo à doação de bens e aquisição de produtos para sua própria casa na aldeia sagrada, onde são recebidos visitantes e 
praticados rituais.

Em suma, há uma complexa economia da cura e do conhecimento, em que espíritos, xinayas e pacientes transacionam com prestações de múltiplas naturezas e regimes, por meio de conversões de dívidas. Relações de parentesco e seus deveres dão origem a prestações sob a forma de cura e conhecimento, mas essas são recompensadas por bens, dinheiro e serviços.

\section{Considerações finais}

Neste artigo foi analisado um fragmento do sistema de trocas Yawanawá e das relações que o animam, por meio de um conjunto de transações que promovem a circulação de bens, serviços e dinheiro. Elas correspondem a dois pares de conversão da dívida, em que obrigações derivadas de posições individuais em relações e serviços prestados são recompensadas por direitos, bens e serviços; estes, por sua vez, geram prestações sob a forma de lealdade política, cura e conhecimento. Esta análise estava a serviço de um argumento e da demonstração de uma perspectiva analítica para examiná-lo.

O argumento é que o sentido e as orientações das transações econômicas residem, para além da satisfação de utilidades individuais, nos compromissos, nas obrigações, nos direitos e nos afetos produzidos por essas relações, ainda que se possa dizer que o cumprimento das obrigações seja semelhante ao modelo utilitarista. As transações são um momento em relações duradouras e fluxos de prestações que operam múltiplos regimes de troca, em formas e medidas socialmente adequadas para atender a dívidas geradas por deveres que advêm dessas relações ou por serviços que são prestados em seu bojo.

Esse argumento geral tem uma dimensão específica para o caso analisado, pois mostra que, entre os Yawanawá, bens, dinheiro e as transações que os fazem circular estão subordinados a objetivos de reprodução social e cultural, fortalecimento da liderança política, manutenção do parentesco e promoção de rituais, ainda que se exija um trabalho para que se observem regras de consumo e expectativas.

A comprovação desse argumento exige uma perspectiva analítica focada nos fluxos de circulação de objetos e pessoas engendrados por laços sociais e espirituais em diferentes regimes, conectando mercado, autoridade, parentesco e cosmologia. A noção de "conversões da dívida", inspirada na obra de Thomas (1991), procura dar conta desse desafio, retomando contribuições anteriores para a análise da troca (Sahlins, 1972) e a sugestão mais recente de investigar circuitos de comércio (Zelizer, 2004). Esta autora propõe um olhar sobre a sequência de operações em que circulam pessoas e objetos, convertendo direitos e deveres em prestações sob a forma de bens e 
serviços com valor e, por sua vez, essas na produção de relações com direitos e deveres.

O primeiro par de conversões analisado revela que a capacidade de manipular trocas e distribuir bens produz uma dívida convertida em lealdade política. A distribuição diferencial, política e afetiva dos recursos obtidos indica a predominância e o enredamento de transações comerciais em relações e padrões de organização locais. Aqui, o dinheiro não nivela todos os participantes, nem rompe as correntes da tradição e está longe de ser a "carta magna da liberdade individual", como teoriza Simmel (1978, p. 286).

O segundo par liga objetos, pessoas e espíritos em operações de troca que procuram produzir o conhecimento e a cura. Os espíritos fornecem a caça e o conhecimento necessário para a cura, exigindo do caçador, do curandeiro e do paciente a observância de interditos alimentares e sexuais. A cura e o conhecimento do curandeiro são recompensados por um fluxo contínuo de alimentos, bens e auxílios, além de eventuais alianças matrimoniais. Nos dois casos, trata-se de dívidas que permanecem abertas, derivadas da posição relacional dos atores e dos serviços que elas promovem.

Ainda que a análise aqui realizada tenha por objeto uma população ameríndia, o instrumento aqui proposto pode ser aplicado às sociedades do centro do capitalismo global. Com efeito, fenômenos empíricos semelhantes a conversões entre bens adquiridos em relações mercantis e deveres de cuidado e criação, além dos afetos próprios ao parentesco, têm sido revelados em sociedades euro-americanas (Zelizer, 2005; Weber, 2013). Contudo, o conteúdo das relações e das prestações, as escalas valorativas e as formas de marcar certos objetos e o dinheiro como próprios de determinadas relações, assim como as regras e os costumes que orientam os participantes nessas conversões, são particulares a cada coletividade e devem ser interpretadas com referência a um sistema de sentido local. Se as relações variam, também variam os enredamentos e seus sentidos.

Extrapolando esses achados e considerando que a dívida e sua prestação podem estar relacionadas com direitos e deveres de um registro diferente, que não apenas doações, como a evidência aqui (ver também Thomas, 1991) indica, cabe indagar se a prestação total do modelo maussiano da dádiva, com sua tríplice obrigação de dar, receber e reciprocar, não se aplicaria para outras formas de troca além da dádiva e poderiam descrever sistemas em que a circulação ocorre em múltiplos regimes. Afinal, a análise aqui empreendida mostrou como as transações são operações de circulação que não correspondem a "simples trocas de bens, de riquezas e de produtos” (Mauss, 2003, p. 190), pois expressam instituições políticas, morais, familiares e preocupações estéticas, constituindo "termos de um contrato bem mais geral e bem mais permanente” (Idem, p. 191), que é a ordem social. Superar a visão que separa os regimes de troca e as formas de prestação adequadas a cada relação para observar 
suas continuidades, alimentando uma rede de laços, permitiria verificar que não são as economias dos outros aquelas que sempre acompanham adjetivos e que seguem os modelos formais do utilitarismo, mas que as economias pensadas como esferas autônomas não o são senão como um recurso ideológico que ofusca o profundo enredamento das atividades de produção, troca e consumo em deveres e preocupações de ordem distinta. A comprovação dessa assertiva resta na análise das conversões da dívida operadas em diferentes contextos da economia global.

\section{Referências Bibliográficas}

Appadurai, Arjun. (1986), "Introduction: commodities and the politics of value". In: (org.). The social life of things: commodities in cultural perspective. Cambridge, Cambridge University Press, pp. 5-63.

Bohannan, Paul (1959). “The impact of money on an African subsistence economy”. Journal of Economic History, 4 (19): 491-503.

CAllon, Michel. (1988), "Introduction: the embeddedness of economic markets in economics". In: (org.). The laws of the markets. Londres, Blackwell, pp. 1-57.

CARRIER, James. (1995), Gifts and commodities: exchange and Western capitalism since 1700. Londres, Routledge.

Clastres, Pierre. (1974), La société contre l'État. Paris, Minuit.

ERIKson, Philippe. (1993), “Une nébuleuse compacte: le macro-ensemble pano”. L'Homme, 126/128 (33): 45-58.

Ferreira, Mariana Kawall Leal. (1997), "When $1+1 \neq 2$ : making mathematics in central Brazil”. American Ethnologist, 1 (24): 132-147.

Frazer, James G. (1922), "Preface”. In: Malinowski, Bronislaw. Argonauts of the Western Pacific. Londres, Routledge \& Kegan Paul, pp. vii-xiv.

FundaÇão Nacional do Índio. (2006), "Relatório de revisão de limites da terra indígena do Rio Gregório - Processo Funai n. 713/2006”. Brasília, Funai.

GIL, Laura Perez. (1999), Pelos caminhos de Yuve: conhecimento, cura e poder no xamanismo yawanawa. Florianópolis, dissertação de mestrado, Centro de Filosofia e Ciências Humanas da Universidade Federal de Santa Catarina.

Godelier, Maurice. (1986), Making of great men: male domination and power among the New Guinea Baruya. Cambridge, Cambridge University Press. (1996), L'énigme du don. Paris, Fayard.

Gordon, Cesar. (2006), Economia selvagem: ritual e mercadoria entre os indios Xikrin-Mebêngôkre. São Paulo/ Rio de Janeiro, Editora Unesp/Isa/Nuti.

GöTz, Norbert. (2015), “'Moral economy': its conceptual history and analytical prospects”. Journal of Global Ethics, 2 (11): 147-162. 
Graeber, David. (2011), Debt: the first 5000 years. Nova York, Melville House.

Granero, Fernando Santos. (1993), "From prisoner of the group to darling of the gods: an approach to the issue of power in lowland South America". L'Homme, 126 (33): 213-230.

Gregory, Chris. (1982), Gifts and commodities. Londres, Academic.

Guimarães, Nadya Araujo. (2016), “Casa e mercado, amor e trabalho, natureza e profissão: controvérsias sobre o processo de mercantilização do trabalho de cuidado". Cadernos Pagu, 46: 59-77.

GuYer, Jane. (2004), Marginal gains: monetary transactions in Atlantic Africa. Chicago, University of Chicago Press.

L'Estolle, Benoît. (2014), “'Money is good, but a friend is better': uncertainty, orientation to the future, and 'the economy'". Current Anthropology, 9 (55): 62-74.

LÉvi-Strauss, Claude. (1955), Tristes tropiques. Paris, Plon.

MalinowsKi, Bronislaw. (1922), Argonauts of the Western Pacific. Londres, Routledge \& Kegan Paul.

Maurer, Bill. (2006), "The anthropology of money”. Annual Review of Anthropology, 35: 15-36.

MAuss, Marcel. (2003), "Ensaio sobre a dádiva: forma e razão da troca nas sociedades arcaicas". In: . Sociologia e antropologia. São Paulo, Cosac Naify, pp. 185-318.

Naveira, Miguel Alfredo Carid. (1999), Yawanawa: da guerra à festa. Florianópolis, dissertação de mestrado, Programa de Pós-Graduação em Antropologia Social da Universidade Federal da Santa Catarina.

PARRY, Jonathan \& BLOCH, Maurice. (1989), "Introduction: money and morality of exchange". In: (orgs.). Money and morality of exchange. Cambridge, Cambridge University Press, pp. 1-32.

SAHLins, Marshall. (1972), Stone age economics. Londres, Routledge.

Scотт, James. (1976), The moral economy of the peasant: rebellion and subsistence in southeast Asia. Princeton, Princeton University Press.

Simmel, Georg. (1978), The philosophy of money. Londres, Routledge \& Kegan Paul.

Sztutman, Renato. (2012), O profeta e oprincipal: a ação politica amerindia e seus personagens. São Paulo, Edusp.

Tномаs, Nicholas. (1991), Entangled objects: exchange, material culture, and colonialism in the Pacific. Cambrige, Harvard University Press.

Thompson, Edward Palmer. (1971), "The moral economy of the English crowd in the eighteenth century”. Past \& Present, 50: 76-136.

Vereta-Nahoum, André. (2016), Selling "cultures": the traffic of cultural representations from the Yawanawa. Colônia, International Max Planck Research School on the Studies on the Political and Social Constitution of the Economy.

Vinnya, Aldaiso Luiz et al. (2006), Costumes e tradições do povo Yawanawá. Rio Branco, Comissão Pró-Índio do Acre/Organização dos Professores Indígenas do Acre.

Weber, Florence. (2013), Penser la parenté aujourd'hui: la force du quotidien. Paris, Rue d'Ulm. 
Zelizer, Viviana. (2004), “Circuits of commerce”. In: Alexander, J. C. et al. (orgs.). Self, social structure and beliefs: explorations in sociology. Berkeley, University of California Press, pp. 122-144.

. (2005), The purchase of intimacy. Princeton, Princeton University Press.

\section{Resumo}

Conversões da dívida entre os Yawanawá: um modelo de análise dos fundamentos culturais, sociais e políticos da troca

Este texto procura demonstrar que a noção de conversões da divida é útil para revelar os enredamentos do dinheiro, das mercadorias e das transações mercantis em uma teia de obrigações políticas, culturais e sociais. Para tanto, mobiliza material coletado durante trabalho de campo para analisar dois pares de conversão da dívida em que circulam bens e dinheiro entre os Yawanawá, uma população nativa do sudoeste amazônico. Nessas conversões, dívidas oriundas de relações políticas, assim como serviços relacionados com rituais e curas, geram prestações sob a forma de dinheiro, bens e serviços. Analisando as conversões da dívida entre os Yawanawá, o texto demonstra que dinheiro e bens são domesticados, colocados a serviço de obrigações políticas, culturais e sociais e não corroem princípios da sociabilidade ou da reprodução cultural, ainda que haja um constante esforço para manter a orientação dessas transações em objetivos comunitários. Palavras-chave: Troca; Conversões da dívida; Obrigações sociais; Amazônia; Yawanawá. 


\section{Abstract}

Conversions of debt among the Yawanawa: an analytical model of the cultural, social and political grounds of exchange

This text proposes the notion of conversions of debt and aims to show its analytical usefulness on revealing the entanglements of money, commodities and market transactions with a web of political, cultural and social obligations. In order to do so, it deploys material collected during fieldwork to analyze two pairs of conversions of debt in which goods and money circulate among the Yawanawa, a native population from southwestern Amazon. In such conversions, debts generated by political relations, as well as ritual and cure services, generate prestations in the form of money, goods and services. Analyzing conversions of debt among the Yawanawa, the text demonstrates that money and goods are domesticated, serving political, cultural and social obligations, and do not corrode principles of sociability or cultural reproduction of the Yawanawa, despite the constant effort to keep these transactions subordinated to community goals. Keywords: Exchange; Conversions of debt; Social obligations; Amazon; Yawanawa.

Texto recebido em 24/8/2016 e aprovado em 9/10/2016. DoI: 10.11606/0103-2070.ts2017. 119612.

ANDRÉ VERETA-NAHOUM é pesquisador de pós-doutorado Fapesp (Processo n. 2014/13285-6) no Centro Brasileiro de Análise e Planejamento (Cebrap) e pesquisador associado ao Núcleo de Estudos em Cultura e Economia (Nucec-UfRJ).E-mail: andre.nahoum@gmail.com. 